\title{
Preparation of Biocompatible Hydrogel from Lignin- Carbohydrate Complex (LCC) as Cell Carriers
}

\author{
Houkuan Zhao, ${ }^{\text {a }}$ Qinghua Feng, ${ }^{a}$ Yimin Xie, ${ }^{* a, b}$ Jinling Li, ${ }^{\text {a }}$ and Xuekuan Chen ${ }^{\text {a }}$ \\ Two poplar lignin-carbohydrate complexes (LCCs), LCC-48 and LCC-72, \\ were isolated at different milling times, $48 \mathrm{~h}$ and $72 \mathrm{~h}$, respectively. A new \\ hydrogel carrier was prepared from these LCCs in the presence of \\ polyethylene glycol diglycidyl ether as the crosslinker for cell (human \\ hepatocyte (L-02)) culture. The effects of the structure of LCC on the \\ carrier were investigated. The FT-IR spectra indicate that the two LCC \\ samples were composed of lignin and polysaccharide, and showed a \\ typical LCC structure. The galactose contents of LCC-48 and LCC-72 \\ were $3.02 \%$ and $5.67 \%$, respectively. The results of cell culture show that \\ a large number of hepatocytes adhered to the porous carriers. \\ Hepatocytes grown on the LCC carriers outperformed the control group in \\ every observed category, including cell proliferation rate and metabolic \\ activity. These results indicate that poplar LCC might be a great potential \\ precursor of biological carriers for human hepatocytes culture.
}

Keywords: Lignin-carbohydrate complexes; Galactose; Hydrogel carrier; Hepatocytes; Biocompatibility

Contact information: a: Research Institute of Pulp \& Paper Engineering, Hubei University of Technology, 430068, Wuhan, China; b: Hubei Provincial Key Laboratory of Green Materials for Light Industry, Hubei University of Technology, 430068, Wuhan, China; *Corresponding author: ppymxie@163.com

\section{INTRODUCTION}

Plant cell walls in higher plants are composed primarily of cellulose, hemicelluloses, and lignin (Vanholme et al. 2010). Some polysaccharides in the cell walls of lignified plants are linked to lignin to form lignin-carbohydrate complexes (LCCs). The lignin-carbohydrate covalent linkages are the most probable cause for residual lignin, which resists delignification during kraft pulping and bleaching (Lawoko et al. 2004). Many experiments with LCCs strongly confirm that such bonds exist between lignin and hemicelluloses (Eriksson et al. 1980; Xie et al. 2000). The proposed linkage type is classified into the following six groups: ether linkage of the hydroxyl group at the position of the lignin side chain with alcoholic hydroxyl of sugar residue (Freudenberg 1965), ester linkage of the alcoholic $\mathrm{OH}$ of lignin with the carboxylic group of uronic acid (Yaku et al. 1976), hemiacetal or acetal linkage of the carbonyl group located at $\beta$-position of lignin with carbohydrates (Bolker 1963), glycoside linkage with the primary alcoholic OH at the $\gamma$-position of the phenylpropane unit (Takahashi and Koshijima 1988), glycosidic linkage at the phenolic OH of lignins (Smelstorius 1974), and ester linkage of the carboxylic group of the cinnamic acid unit in lignin with the alcoholic $\mathrm{OH}$ of carbohydrates (Lam et al. 1992). LCCs are a promising, eco-friendly, and renewable source for generating energy, fuels, and chemicals that could partially replace fossil fuels to reduce the pressure of environmental pollution problems (Ma et al. 2015). However, LCC as a precursor for biological material has rarely been reported. 
LCC contains hydrophilic, flexible polysaccharide chains and hydrophobic rigid lignin blocks. This structure makes LCC have good biocompatibility and mechanical strength (Kai et al. 2016). The polysaccharide moiety consists of various types of sugars such as galactose, glucose, arabinose, mannose, fucose, and occasionally uronic acid, depending on the plant species (Hiroshi et al. 2005). The biocompatibility and biodegradability of LCC are still uncertain and need more study (Sakagami et al. 2010). LCCs may be used as good biological carriers for hepatocyte culture. In recent years, LCCs isolated from ginkgo wood (Ginkgo biloba L.) have shown satisfactory biocompatibility (Li et al. 2014), and the hydrogel prepared from artificial LCCs, dehydrogenation polymer (DHP)-galactose complex, has good biocompatibility with human hepatocytes (Wu et al. 2016). However, further investigations of the effect of LCC structure on the biocompatibility of hydrogel carrier, especially the LCC extracted via different ball milling time, have not been reported.

In the present work, hydrogel carriers were prepared from poplar LCCs in the presence of polyethylene glycol diglycidyl ether as the crosslinker for cell (human hepatocytes (L-02)) cultures. The LCCs were investigated in terms of its structure, components, and relative molecular weight. The growth state of human hepatocytes on the biological carriers was observed by inverted microscope and scanning electron microscopy (SEM). The effects of the LCC structure of the carrier on the metabolic activity of hepatocytes were investigated by determining albumin in culture medium, blood urea nitrogen content, and glucose consumption.

\section{EXPERIMENTAL}

\section{Materials}

Poplar tree (Populus euramericana) wood was obtained from Wuhan botanical garden (Wuhan, China). Human hepatocytes were provided by the Pricells company (Wuhan, China). Polyethylene glycol diglycidyl ether, average $M_{\mathrm{n}} 500$ (500g/mol), was purchased from Sigma Chemistry Co. (Shanghai, China). HPLC-grade N,Ndimethylformamide was purchased from Aladdin (Shanghai, China). Insulin was obtained from Biosharp (Beijing, China). Fetal bovine serum was provided by MP Biomedicals (California, USA). All other reagents were obtained from Sangon Biotechnology (Shanghai, China) or as indicated in the methods.

\section{Methods}

\section{Preparation of poplar LCC}

Poplar wood meal was extracted with a 2:1 mixture (by volume) of benzene and ethyl alcohol, followed by hot water extraction and vacuum drying for 7 days. The extractive-free wood meal was further ground for $48 \mathrm{~h}$ and $72 \mathrm{~h}$ in a vibration ball mill with water cooling. The LCC obtained by ball milling for $48 \mathrm{~h}$ was named LCC-48. The LCC obtained by ball milling for $72 \mathrm{~h}$ was called LCC-72. The poplar LCC was then purified as described previously (Björkman 1957), as shown in Fig. 1. The yield of LCC-48 and LCC72 were $13.8 \%$ and $17.3 \%$, respectively. 


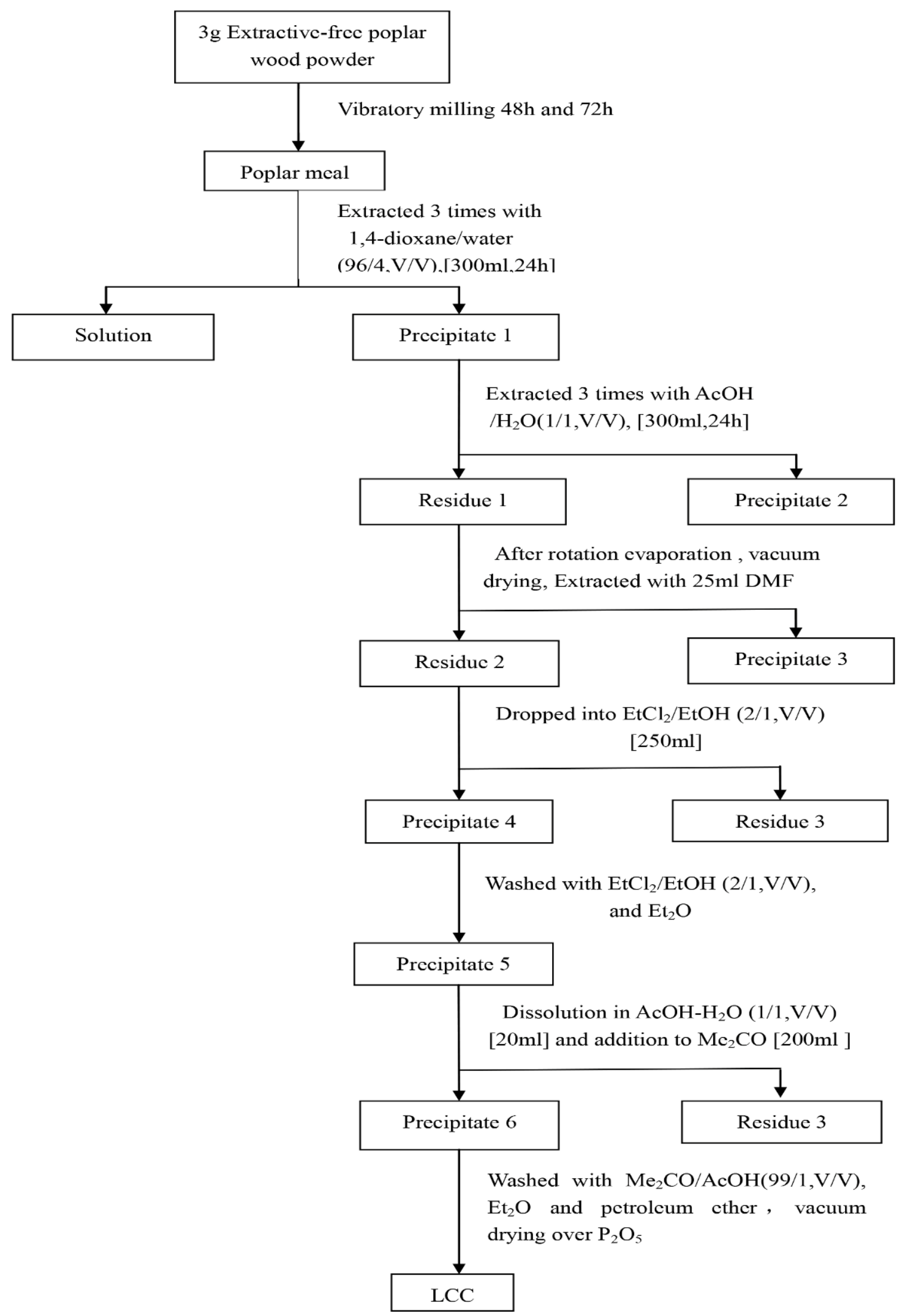

Fig. 1. Isolation of LCC from popular wood by vibratory ball milling for $48 \mathrm{~h}$ or $72 \mathrm{~h}$ 


\section{Preparation of LCC carriers}

Poplar LCC-48 (100 mg) and poplar LCC-72 (100 mg) isolated by ball milling were placed in different test tubes, then $\mathrm{NaOH}$ solution $(200 \mu \mathrm{L}, 3.3 \mathrm{~mol} / \mathrm{L})$ was added to the tubes. Subsequently, the mixtures were then stirred in an ice bath for $4 \mathrm{~h}$ until the LCC completely dissolved. To the above solutions, polyethylene glycol diglycidyl ether $(50 \mu \mathrm{L})$ was added and further stirred until all polyethylene glycol diglycidyl ether was dissolved. This suspension was then stirred at $50{ }^{\circ} \mathrm{C}$ for $24 \mathrm{~h}$ to obtain hydrogel porous biological carriers. These were subsequently added to an Erlenmeyer flask. The material was washed with distilled water until the water became clear and the solution reached $\mathrm{pH} 7$. The samples were then freeze-dried for $24 \mathrm{~h}$. The carrier obtained with LCC-48, which was obtained by ball milling for $48 \mathrm{~h}$ is named LCC-48-C, while the carrier prepared with LCC72 is named LCC-72-C.

\section{FT-IR determination of LCC}

Fourier transform infrared (FT-IR) spectrum was recorded on a Thermo Scientific Nicolet 6700 (Waltham, MA, USA) using the KBr pellet technique. For each spectrum, the scans were stored at a resolution of $2 \mathrm{~cm}^{-1}$ over the range of $4000 \mathrm{~cm}^{-1}$ to $500 \mathrm{~cm}^{-1}$.

\section{Chemical composition of LCC}

Sugar contents were measured according to the previous literature (Huang et al. 2015; Min et al. 2014). A two-step acid hydrolysis procedure was applied to fractionate the biomass into two forms, i.e., acid-soluble sugars and acid-insoluble lignins, that are more easily quantified. Sugars hydrolyzed into the monomeric forms in the hydrolysis liquid were determined by high performance liquid chromatography (HPLC) (Shimadzu LC-20AT, Kyoto, Japan) with a differential refractive index detector (Shimadzu RID-10A) on an Aminex HPX-87P column (Bio-Rad, Hercules, CA, USA) running at a flow rate of $0.6 \mathrm{~mL} / \mathrm{min}$ at $65^{\circ} \mathrm{C}$, with water as the moving phase.

The acid-insoluble lignin was determined according to the method described by Ibáñez and Bauer (2014). The content of acid-soluble lignin was determined as follows. One gram of woody material was treated with concentrated sulfuric acid (72 wt.\%) at 18 ${ }^{\circ} \mathrm{C}$ for $2 \mathrm{~h}$. After water was added to dilute the $\mathrm{H}_{2} \mathrm{SO}_{4}$ to $3 \mathrm{wt}$. $\%$, the mixture was heated to boiling for $4 \mathrm{~h}$ with a continuous addition of water to keep a stable level of water in the flask. The mixture was then filtered in vacuo with a $\mathrm{G} 4$ glass filter. The obtained acidinsoluble lignin was dried at $105^{\circ} \mathrm{C}$ overnight. The filtrate was used to determine the acidsoluble content by a UV-Vis spectrometer (Shimadzu 2550, Japan) at wavelength of $205 \mathrm{~nm}$ according to the method described by Lin. (Lin and Dance 1992).

\section{Molecular weight determination}

The lignin was dissolved in N,N-dimethylformamide (DMF, $1 \mathrm{mg} / \mathrm{ml}$ ) and passed through a $0.45 \mu \mathrm{m}$ membrane filter. The molecular weight of lignin was determined by gel permeation chromatography (GPC) (Shimadzu, Kyoto, Japan) with a refractive index detector with DMF as the eluent $\left(1.0 \mathrm{~mL} / \mathrm{min}\right.$ ), injecting $25 \mu \mathrm{L}$ at $40{ }^{\circ} \mathrm{C}$ (Abdelaziz et al. 2016).

\section{SEM observation of the LCC carriers and adhering hepatocytes}

The hydrogel bio-carriers in the experimental group were taken out on the $5^{\text {th }}$ day during the culture of human hepatocyte in vitro. After being stabilized with $2.5 \%$ glutaraldehyde (GA) for $24 \mathrm{~h}$ followed by treatment with osmic oxide for $1 \mathrm{~h}$, the carriers 
were sequentially dehydrated with $30 \%, 50 \%, 70 \%, 80 \%, 90 \%$, and $100 \%$ ethanol, washed with phosphate-buffered saline (PBS), and vacuum-dried at $40{ }^{\circ} \mathrm{C}$. The dried samples were adhered to a copper with adhesive then sprayed with a layer of metal film in vacuum evaporator. Scanning electron microscopy was conducted on a JSM-6390LV (Electronics Co., Ltd., Tokyo, Japan), which was used to observe the morphological structure of the surface and cutting section.

\section{Cell culture of human hepatocytes}

Human hepatocytes (L-02) were purchased from Pricells Company (Wuhan, China). The cell culture was washed with PBS buffer twice and digested with $0.25 \%$ trypsin for 1 to $2 \mathrm{~min}$. After the digestive solution was removed, 20\% (by volume) fetal bovine serum was further supplemented to the medium. Insulin $(0.01 \mathrm{mg} / \mathrm{mL})$, and doubleantibody $1 \times$ RPMI-164 was added to the medium to culture the hepatocytes. The culture medium in the flask was mixed with a pipette until all of the parietal cells were in solution. The culture medium was transferred to a sterile tube and centrifuged at $800 \mathrm{rpm}$ for $5 \mathrm{~min}$, and the supernatant was decanted (Muhammad et al. 2011; Shadforth et al. 2012). The cells were resuspended in a complete culture medium.

Human hepatocyte suspension at a density of about $5 \times 10^{4}$ cells $/ \mathrm{mL}$ was prepared in advance. The LCC carriers were sterilized in dry state at $165^{\circ} \mathrm{C}$ for $2 \mathrm{~h}$ and seeded in 24-well culture plates. In the control group, the cultured cells were not added to LCC carriers. Cell suspensions $(100 \mu \mathrm{L})$ were added to each well and then were supplemented with the complete culture solution $(900 \mu \mathrm{L})$ under a humid atmosphere containing $5 \% \mathrm{CO}_{2}$ at $37^{\circ} \mathrm{C}$.

\section{Cell counts}

For one week of the culture of human hepatocytes (L-02), the liquid mediums were collected every day in a clean bench, and the cells were washed twice with phosphate buffer followed by $0.25 \%$ trypsin digestion for $1 \mathrm{~min}$ to $2 \mathrm{~min}$. After the digestive juice was removed, new medium was added to terminate the digestion. The cells were dissociated into a single cell suspension. Cell suspensions $(200 \mu \mathrm{L})$ were stained with $0.4 \%$ trypan blue solution and placed on a hemacytometer for counting on a Leica DM-6000 CS microscope (Leica Instruments Inc., Wetzlar, Germany).

\section{Observation by inverted microscope}

After one week of culture, human hepatocytes (L-02), LCC-72-C, LCC-48-C, and the control group were observed with an inverted biological microscope (COXEM EM-30 Plus, Shanghai, China).

\section{Detection of metabolic activity}

The content of albumin was determined with a commercially available kit (provided by Nanjing Jiancheng Bioengineering Institute, China). The culture medium of the LCC carriers and the control group was collected every day for one week. In test tubes, $10 \mu \mathrm{L}$ of the control (distilled water), standard (albumin, $34.8 \mathrm{~g} / \mathrm{L}$ ), or sample (cell supernatant) was mixed with bromocresol green buffer $(2.5 \mathrm{~mL})$. The solution was incubated for $10 \mathrm{~min}$ at room temperature. The absorbance at $628 \mathrm{~nm}$ was measured on an UV-Vis spectrophotometer (Shimadzu 2550, Kyoto, Japan). The albumin content was calculated as follows, 


$$
A L B=\left(A_{1}-A_{2}\right) /\left(A_{0}-A_{2}\right) \times C_{0}
$$

where $A L B$ is the content $(\mathrm{g} / \mathrm{L})$ of albumin, $A_{0}, A_{1}$, and $A_{2}$ are the absorbance values of standard tubes, sample tubes, and control tubes, respectively, and $C_{0}(\mathrm{~g} / \mathrm{L})$ is the concentration of a standard.

The content of urea nitrogen was determined by a commercially available kit (provided by Nanjing Jiancheng Bioengineering Institute, China). The culture medium of the LCC carriers and control group were collected every day for one week. Distilled water $(20 \mu \mathrm{L})$, standard urea nitrogen $(10 \mathrm{mmol} / \mathrm{L})$, and cell-free suspension were mixed with oxime solution $(1 \mathrm{~g} / \mathrm{L}, 1 \mathrm{~mL})$ and a solution of sulfuric acid $(0.824 \mathrm{~mol} / \mathrm{L})$ mixed with phosphoric acid $(1.135 \mathrm{~mol} / \mathrm{L})(1 \mathrm{~mL})$ in test tubes. The solutions were heated in a boiling water bath for 15 min and then rapidly cooled in an ice bath. The absorption at $520 \mathrm{~nm}$ were monitored by a UV-Vis spectrophotometer (Shimadzu 2550). The nitrogen content was calculated as follows,

$$
B U N=\left(A_{1}-A_{2}\right) /\left(A_{0}-A_{2}\right) \times C_{0}
$$

where $B U N$ is the content ( $\mathrm{mmol} / \mathrm{L}$ ) of nitrogen, $A_{0}, A_{1}$, and $A_{2}$ are the absorbance values of standard tubes, sample tubes, and control groups, respectively, and $C_{0}(\mathrm{~g} / \mathrm{L})$ is the concentration of a standard.

The glucose content was determined by a commercially available kit (provided by Nanjing Jiancheng Bioengineering Institute, China). The culture medium of the experimental group was collected every day for one week. In test tubes, $10 \mu \mathrm{L}$ of distilled water, standard glucose, or cell-free supernatant was mixed with a solution consisting of phosphate buffer ( $\mathrm{pH} 7.0$ ), $10.6 \mathrm{mmol} / \mathrm{L}$ phenol, and $70 \mathrm{mmol} / \mathrm{L}$ aminoantipyrine. The reaction was incubated for $15 \mathrm{~min}$ at $37{ }^{\circ} \mathrm{C}$. The absorption values were measured at 505 $\mathrm{nm}$ by an UV-Vis spectrophotometer (Shimadzu 2550). The glucose content was calculated as follows,

$$
C=\left(A_{1} / A_{0}\right) \times C_{0}
$$

where $C$ is the content $(\mathrm{mmol} / \mathrm{L})$ of glucose, $A_{0}$ and $A_{1}$ are the absorbance values of standard tubes and sample tubes and respectively, and $C_{0}(\mathrm{~g} / \mathrm{L})$ is the concentration of a standard.

\section{RESULTS AND DISCUSSION}

\section{FT-IR Analysis}

The LCC structure was analyzed by FT-IR spectrometry. As shown in Fig. 2 and Table 1, there was no significant difference between LCC-48 and LCC-72, which are composed of lignin and polysaccharide, with a typical structure of lignin-carbohydrate complexes. The FT-IR spectra of the two samples show a strong absorbance at 3428.2 to $3434.4 \mathrm{~cm}^{-1}$ from the $-\mathrm{OH}$ and at 2918.7 to $2919.1 \mathrm{~cm}^{-1}$ from $-\mathrm{CH}$ stretching vibration. The absorption band at 1738.1 to $1732.2 \mathrm{~cm}^{-1}$, which indicated the presence of $\mathrm{C}=\mathrm{O}$ unconjugated bonds was more intense in the spectrum of LCC-48 because the LCC-48 contained more hemicellulose. The absorption peaks at $1594.9 \mathrm{~cm}^{-1}$ and $1506.5 \mathrm{~cm}^{-1}$ indicated that these are the vibration peaks of the aromatic ring in a basic lignin structure. A peak appearing at 1376.1 to $1378.3 \mathrm{~cm}^{-1}$ in the two samples was assigned to the vibration of aromatic rings (Singh et al. 2005; You et al. 2015). A strong absorption at 1045.3 to 
$1045.7 \mathrm{~cm}^{-1}$ was attributed to the $\mathrm{C}-\mathrm{O}$ stretch of polysaccharides. These results indicated that the LCCs are composed of lignin moieties and sugar units of polysachride.

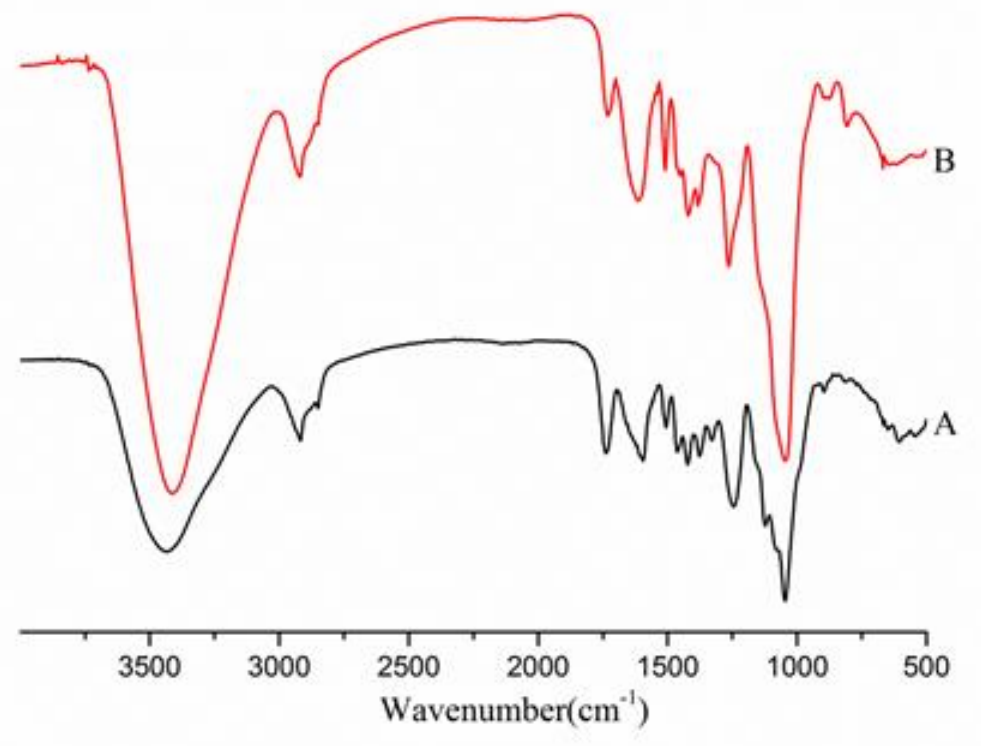

Fig. 2. The FT-IR spectroscopy of LCC-48 (A) and LCC-72 (B)

Table 1. Assignment of Main Characteristic FT-IR bands of LCC-48(A) and LCC72(B)

\begin{tabular}{|c|c|c|c|}
\hline \multicolumn{2}{|c|}{ Wavenumber $\left(\mathrm{cm}^{-1}\right)$} & \multirow[t]{2}{*}{ Assignment } & \multirow[t]{2}{*}{ Reference } \\
\hline A & $B$ & & \\
\hline 3434.4 & 3428.2 & $\mathrm{O}-\mathrm{H}$ stretch & Shivakumar et al.2017 \\
\hline 2918.7 & 2919.1 & C-H stretch & $\begin{array}{c}\text { Zhang et al. 2017; } \\
\text { Shivakumar et al.2017 }\end{array}$ \\
\hline 1738.1 & 1732.2 & $\begin{array}{c}\text { Unconjugated } \mathrm{C}=\mathrm{O} \\
\text { stretch and acetyl } \\
\text { groups in } \\
\text { hemicellulose }\end{array}$ & Durmaz et al. 2016 \\
\hline 1594.9 & 1605.9 & Aromatic ring in lignin & Naumann et al. 2005 \\
\hline 1506.5 & 1508.8 & $\begin{array}{l}\text { Aromatic skeletal } \\
\text { vibration in lignin }\end{array}$ & Durmaz et al. 2016 \\
\hline 1463.2 & 1458.2 & $\begin{array}{l}\text { C-H deformation } \\
\text { (asymmetric) }\end{array}$ & $\begin{array}{c}\text { Hon et al. } 2000 \\
\text { Durmaz et al. } 2016\end{array}$ \\
\hline 1376.1 & 1378.3 & $\begin{array}{l}\text { C-H deformation } \\
\text { vibration }\end{array}$ & $\begin{array}{l}\text { Zhang et al. 2017; } \\
\text { Durmaz et al. } 2016\end{array}$ \\
\hline 1329.2 & - & $\begin{array}{l}\text { Syringyl ring breathing } \\
\text { with } \mathrm{C}-\mathrm{O} \text { stretch in } \\
\text { lignin }\end{array}$ & Hon et al. 2000 \\
\hline 1263.7 & 1263.8 & $\begin{array}{c}\text { Guaiacyl ring plus } \\
\mathrm{C}=\mathrm{O} \text { stretch }\end{array}$ & $\begin{array}{c}\text { Hon et al. } 2000 \\
\text { Durmaz et al. } 2016\end{array}$ \\
\hline 1045.7 & 1045.3 & $\begin{array}{l}\text { C-O stretch in } \\
\text { carbohydrates }\end{array}$ & Durmaz et al. 2016 \\
\hline
\end{tabular}




\section{Chemical Composition of LCC}

The compositions of the two LCC samples were analyzed as described previously (Gao et al. 2015). The solid received after the two-step acid hydrolysis was acid insoluble lignin. The solution was used for sugar and acid soluble lignin determination. Table 2 shows the effect of different milling times on the composition of the poplar LCC. In this experiment, there was no correction for the lost of sugars during hydrolysis of LCC by $\mathrm{H}_{2} \mathrm{SO}_{4}$. Some hemicellulose components were degraded by acid in the hydrolysis process. For example, a part of xylan was converted to furfural. Therefore, the sugar analysis of LCC can be regarded as preliminary. Galactose is recognized by the receptors on liver cells with high physiological activity to hepatocytes (Kim et al. 2006). Galactose enhances the selective interaction between biological carriers and hepatocytes. As shown in Table 1, the galactose contents in LCC-48 and LCC-72 were $3.0 \%$ and $5.7 \%$, respectively. Obviously, LCC-72 contained more galactose units than that of LCC-48. Thus, LCC-72 was more compatible for hepatocytes than LCC-48. The lignin and total sugar contents of LCC-72 were $27.5 \%$ and $61.4 \%$, respectively, which will lead to good physical strength of LCCbased porous biological carriers. Because the lignin contents of LCC-72 was lower than that of LCC-48, the carriers prepared from the LCC-72 may be more flexible and suitable than that from LCC-48.

Table 2. Chemical Composition (\%) of Poplar LCCs

\begin{tabular}{|l|c|c|c|c|c|c|c|c|c|}
\hline Samples & $\begin{array}{c}\text { acid- } \\
\text { insoluble } \\
\text { lignin }\end{array}$ & $\begin{array}{c}\text { acid- } \\
\text { soluble } \\
\text { lignin }\end{array}$ & $\begin{array}{c}\text { Total } \\
\text { lignin }\end{array}$ & Glucose & Xylose & Galactose & Arabinose & Mannose & $\begin{array}{c}\text { Total } \\
\text { sugar }\end{array}$ \\
\hline LCC-48 & 28.9 & 3.4 & 32.3 & 6.8 & 29.9 & 3.0 & 3.8 & 8.7 & 52.2 \\
\hline LCC-72 & 22.3 & 5.2 & 27.5 & 4.8 & 33.2 & 5.7 & 4.3 & 13.5 & 61.5 \\
\hline
\end{tabular}

\section{Molecular Weight Determination}

As LCC is a kind of homogenous natural polymer in which lignin and carbohydrates connect each other, not a mixture of lignin fraction and carbohydrate composition, the molecular weight can be determined by GPC. The weight-average molecular weight $\left(M_{\mathrm{w}}\right)$, number-average molecular weight $\left(M_{\mathrm{n}}\right)$, and polydispersity $\left(M_{\mathrm{w}} / M_{\mathrm{n}}\right)$ in LCC-48 and LCC-72 with different ball milling times are shown in Table 2. LCC-48 and LCC-72 had a relative narrow polydispersity as shown by $\mathrm{Mw} / \mathrm{Mn}<1.8$. The number-average molecular weights of LCC samples with different ball billing times were between 7,000 g/mol and 10,000 g/mol. The results indicated that LCC-72 had a lower molecular weight. Molecular weight decreased with the extension of ball milling time. Generally, the molecular weight of the LCC samples was relatively low for preparation of bio-carrier. Therefore, it should be cross-linked during the preparation of bio-carrier to increase the strength and stability.

Table 2. Weight-Average $\left(M_{\mathrm{w}}\right)$, Number-Average $\left(M_{\mathrm{n}}\right)$ Molecular Weights, and Polydispersity Indexes $\left(M_{\mathrm{w}} / M_{\mathrm{n}}\right)$ of LCC-48 and LCC-72

\begin{tabular}{|c|c|c|c|}
\hline Samples & $M_{\mathrm{w}}$ & $M_{\mathrm{n}}$ & $M_{\mathrm{w}} / M_{\mathrm{n}}$ \\
\hline LCC-48 & 17558 & 9836 & 1.785 \\
\hline LCC-72 & 9786 & 7153 & 1.370 \\
\hline
\end{tabular}




\section{SEM Observation of the Morphology of Biological Carriers and Adhering Hepatocytes}

The hydrogel carriers had a good porosity and specific surface area as observed by SEM. As shown in Fig. 3, the pore size of LCC-72-C was more suitable for the growth of human hepatocytes than that of LCC-48-C and control sample (without LCC). As shown in Fig. 3, liver cells adhered to the surface of porous biological carriers. The morphology of the spherical bio-carrier demonstrated that the LCC fraction of poplar wood is a suitable material for cell bio-carriers.

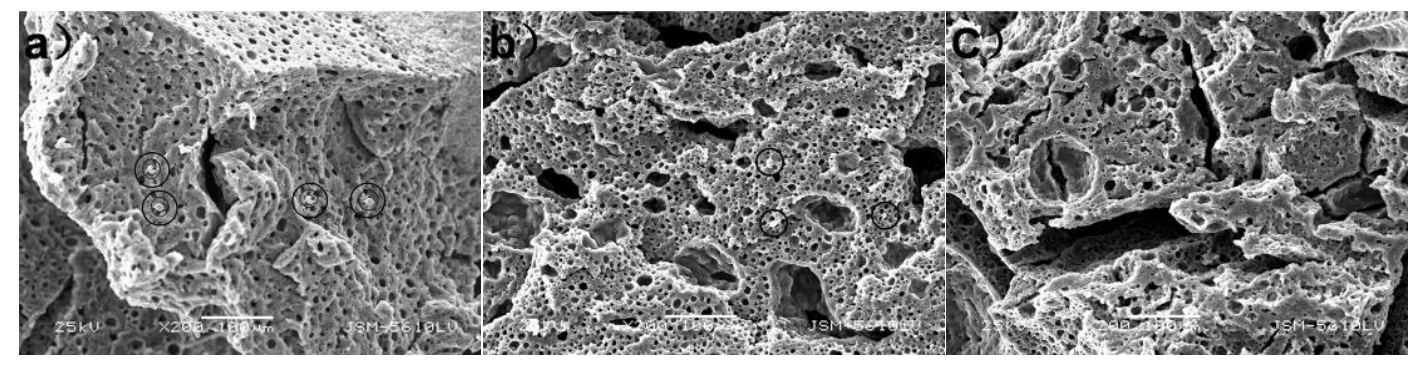

Fig. 3. Adhesion of cells in the porous carriers observed by SEM. (a) LCC-72-C; (b) LCC-48-C; (C) control sample

\section{Cell Counts}

As shown in Fig. 4, the cell number reached its highest values on the $5^{\text {th }}$ day. The highest values of cell numbers of LCC-72-C, LCC-48-C, and the control experiment were $1.84 \times 10^{5}$ cells, $1.68 \times 10^{5}$ cells, and $1.32 \times 10^{5}$ cells, respectively. The cell number of LCC-72-C was obviously superior to those of LCC-48-C and control group. Therefore, LCC-72-C has better biological compatibility, and it could be used as a potential carrier for human cell culture in vitro (Park et al. 2003).

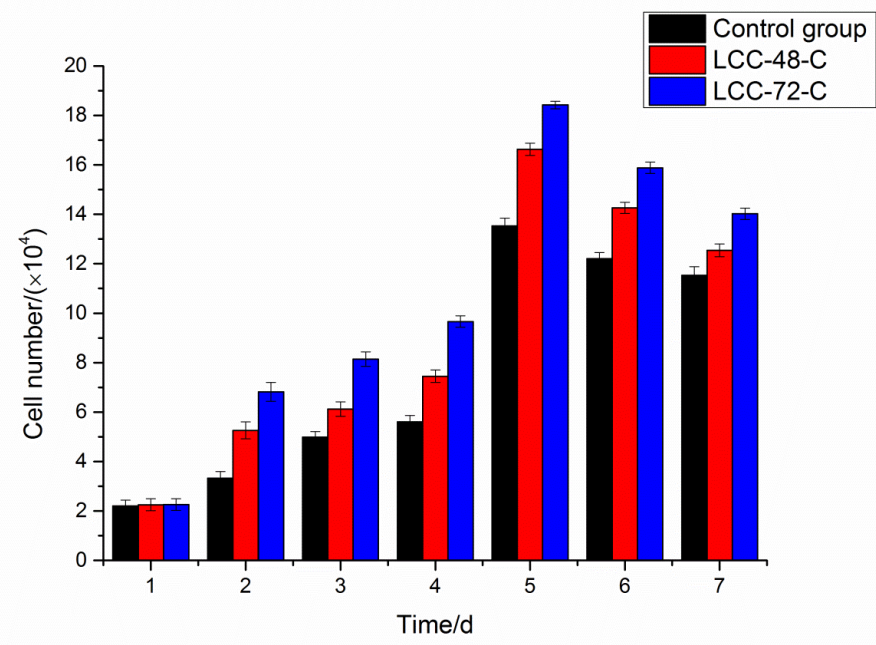

Fig. 4. Cell counting of human hepatocytes cultured in LCC-48-C medium, LCC-72-C medium, and the control group

\section{Observations by Inverted Microscope}

Inverted microscopy observations showed that hepatocytes adhered to the surface of porous carriers. As shown in Fig. 5, the number of active cells adhered to LCC-72-C was considerably more than those of LCC-48-C and the control group. These results also indicate that LCC-72-C had better biocompatibility. 


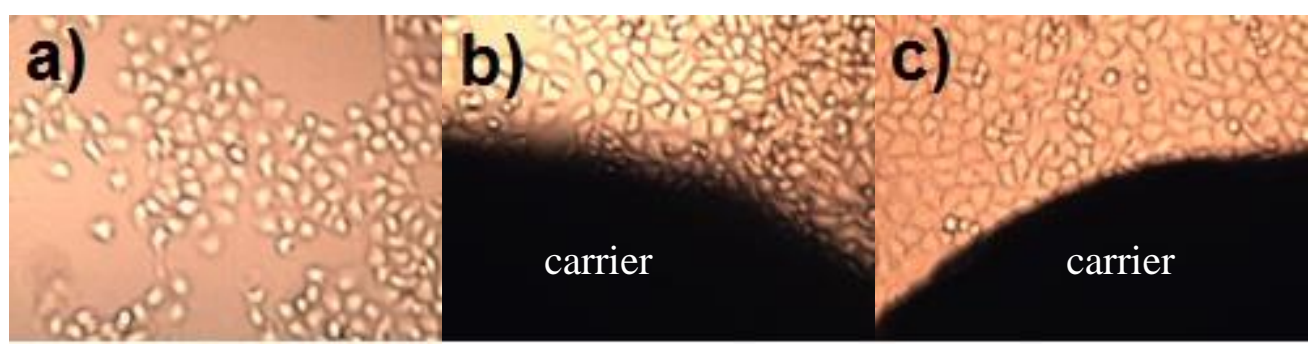

Fig. 5. The hepatocytes cultured on the fifth day of the control group (a), LCC-48-C (b), and LCC$72-\mathrm{C}(\mathrm{c})$

\section{Detection of Metabolic Activity}

Albumin content

As shown in Fig. 6, the activity of albumin secretion (ALB) of human hepatocytes prepared by LCC-72-C, LCC-48-C, and the control group increased during the first 5 days and reached the highest value in the fifth day. The highest values of albumin secretion of LCC-72-C, LCC-48-C, and the control experiment were $16.027 \mathrm{~g} / \mathrm{L} / \mathrm{d}, 14.173 \mathrm{~g} / \mathrm{L} / \mathrm{d}$, and $10.428 \mathrm{~g} / \mathrm{L} / \mathrm{d}$, respectively. The release of albumin (ALB) from the metabolism of hepatocytes of LCC-72-C medium was considerably superior to those of the LCC-48-C and control group during the culture process when the porous bio-carriers were applied. These results indicated that LCC-72-C has good biocompatibility for human hepatocyte culture.

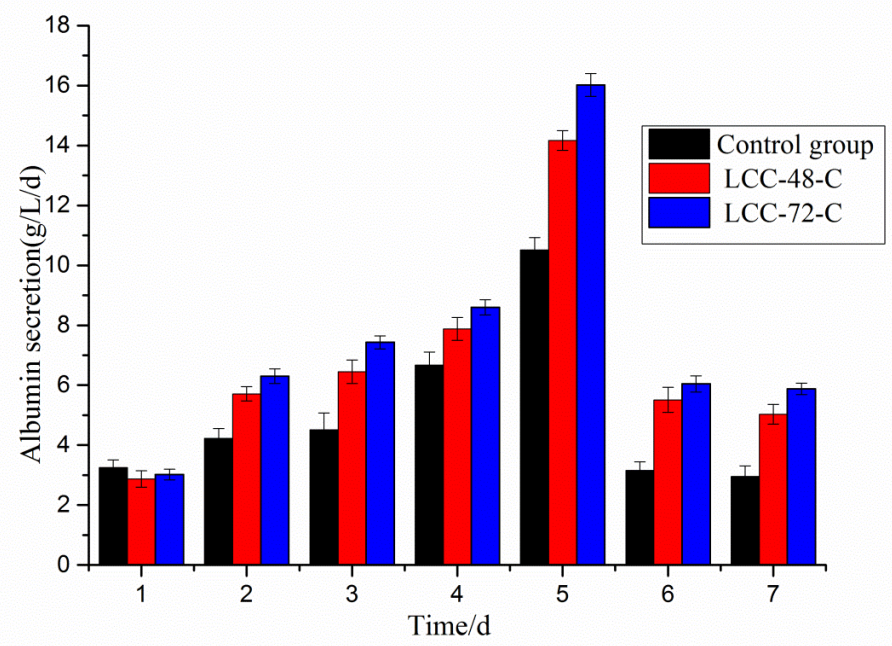

Fig. 6. Albumin secretion of human hepatocytes cultured in the carriers LCC-48-C, LCC-72-C, and the control group

\section{Blood urea nitrogen}

As shown in Fig. 7, the blood urea nitrogen (BUN) content released from human hepatocytes in LCC-72-C, LCC-48-C, and the control group increased during the first five days and reached the highest value in the cultivation of the $5^{\text {th }}$ day. The highest values of BUN content of LCC-72-C, LCC-48-C, and the control experiment were $3.156 \mathrm{mmol} / \mathrm{L} / \mathrm{d}$, $2.873 \mathrm{mmol} / \mathrm{L} / \mathrm{d}$, and $1.268 \mathrm{mmol} / \mathrm{L} / \mathrm{d}$, respectively. The BUN content of LCC-72-C was higher than that of LCC-48-C and the control group. These results indicated that human liver cells cultured in LCC-72-C carriers had higher metabolic activity. 


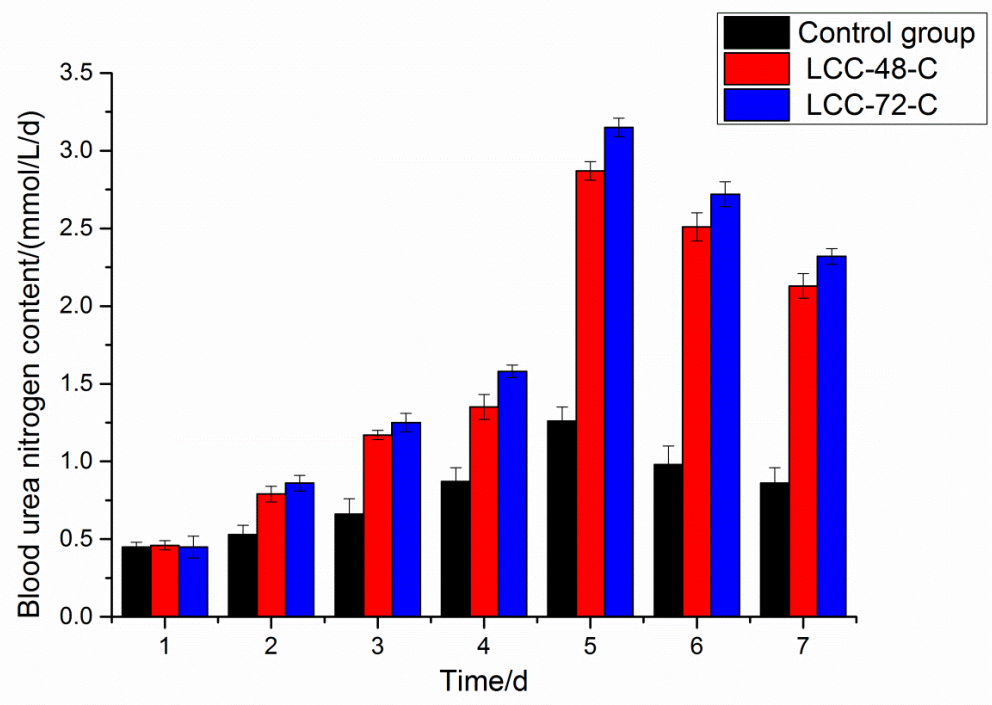

Fig. 7. Blood urea nitrogen of human hepatocytes cultured in the carriers of LCC-48-C, LCC-72$\mathrm{C}$, and the control group

\section{Glucose consumption determination}

As shown in Fig. 8, glucose consumption in human hepatocytes (L-02) cultured in LCC-72-C, LCC-48-C, and the control group reached the highest value on the $5^{\text {th }}$ day of cultivation. The highest values of glucose consumption of the cells cultured in LCC-72-C, LCC-48-C, and the control group were $8.162 \mathrm{mmol} / \mathrm{L} / \mathrm{d}, 7.084 \mathrm{mmol} / \mathrm{L} / \mathrm{d}$, and 6.823 $\mathrm{mmol} / \mathrm{L} / \mathrm{d}$, respectively.

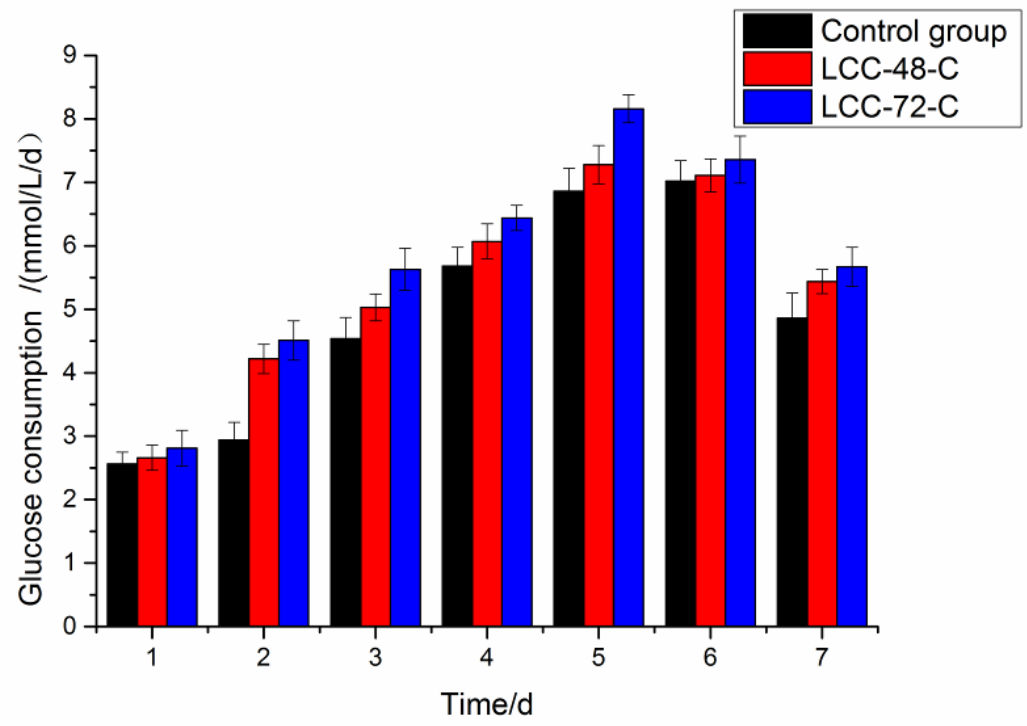

Fig. 8. Glucose consumption of human hepatocytes cultured in the carriers LCC-48-C, LCC-72-C, and the control group

These results showed that LCC-72-C was considerably superior to LCC-48-C and the control group. These results indicated that the carriers prepared with poplar LCC-72-C have satisfactory biocompatibility with human liver cells. Therefore, the LCC-72-C is a 
promising biomedical carrier in the tissue engineering of the culture of liver organs from human liver cells.

\section{CONCLUSIONS}

1. The porous biological carriers were prepared from lignin-carbohydrate complexes isolated by $48 \mathrm{~h}$ and $72 \mathrm{~h}$ ball milling of poplar wood and with gelation forming method. Optical and scanning electron microscopy showed that poplar LCC-based porous carriers can provide a biocompatible medium for liver cell growth.

2. FT-IR spectra showed that the two LCCs are composed of lignin and polysaccharide, with a typical structure of lignin-carbohydrate complexes. The flexible hydrophilic polysaccharide fragments and rigid hydrophobic lignin fragments provide porous biological carriers with high strength and good amphipathicity, which meets the basic requirements of natural medical materials. LCC-48 and LCC-72 indicated contained $3.02 \%$ and $5.67 \%$ galactose, respectively. Thus, carriers prepared with LCC-72 have good compatibility with liver cells because galactose can be recognized by hepatocyte receptors.

3. A large number of liver cells adhered to the porous biological carrier. Cell proliferation was the fastest in LCC-72-C. The proliferation of hepatocytes in the LCC-72-C was also substantially higher than that of LCC-48-C and the control group. Albumin secretion (ALB) value, blood urea nitrogen, and glucose consumption of the LCC-72$\mathrm{C}$ was considerably superior to those of the LCC-48-C and control group when the hepatocytes were cultured in the bio-carriers. These results indicate that LCC-72-C was more biocompatible and shows promise for use as a biomaterial in the culture of human hepatocytes.

\section{ACKNOWLEDGMENTS}

The authors are grateful for the support of the Nature Science Foundation of China (grant No.31370574 and No.31300494) and Hubei Provincial Key Laboratory of Green Materials for Light Industry (Q20131402).

\section{REFERENCES CITED}

Abdelaziz, O. Y., Brink, D. P., Prothmann, J., Ravi, K., Sun, M., García-Hidalgo, J., Sandahl, M., Hulteberg, C. P., Turner, C., Lidén, G., et al. (2016). "Biological valorization of low molecular weight lignin," Biotechnol. Adv. 34(8), 1318-1346. DOI: 10.1016/j.biotechadv.2016.10.001

Björkman, A. (1957). "Lignin and lignin-carbohydrate complexes," Industrial \& Engineering Chemistry 49(9), 1395-1398. DOI: 10.1021/ie50573a040

Bolker, H. I. (1963). "A lignin carbohydrate bond as revealed by infra-red spectroscopy," Nature. 197(4866), 489-490. DOI: 10.1038/197489a0

Durmaz, S., Özlem, Ö., Ismail, H., Ümit, C., Emir, E. (2016). "Examination of the chemical changes in spruce wood degraded by brown-rot fungi using FT-IR and FT- 
Raman spectroscopy," Vib. Spectrosc. 85, 202-207. DOI:

10.1016/j.vibspec.2016.04.020

Eriksson, Ö., Goring, D. A. I., and Lindgren, B. O. (1980). "Structural studies on the chemical bonds between lignins and carbohydrates in spruce wood," Wood Sci. Technol. 14(4), 267-279. DOI: 10.1007/bf00383454

Freudenberg, K. (1965). "Lignin: Its constitution and formation from p-hydroxycinnamyl alcohols," Science 148(3670), 595-600. DOI: 10.1126/science.148.3670.595

Gao, L., Demao, L., Gao, F., Liu, Z. Hou, Y., Chen, S., and Zhang, D. (2015). "Hydroxyl radical-aided thermal pretreatment of algal biomass for enhanced biodegradability," Biotechnology for Biofuels 8(1), 194-198. DOI: 10.1186/s13068-015-0372-2

Hiroshi, S., Ken H., Fumika S., Takako O., Takako O., Kazue S., Hideyuki I., Tsutomu H., Tsutomu H., Sei-ichiro F. (2005). "Molecular requirements of lignincarbohydrate complexes for expression of unique biological activities," Phytochemistry 2108-2120. DOI: 10.1016/j.phytochem.2005.05.013

Hon, D., and Shiraishi, N. (2000). Wood and Cellulosic Chemistry, Revised, and Expanded," CRC Press, Florida, USA

Huang, C., He, J., Li, X., Min, D., and Yong, Q. (2015). "Facilitating the enzymatic saccharification of pulped bamboo residues by degrading the remained xylan and lignin-carbohydrates complexes," Bioresource Technol. 192, 471-477. DOI: 10.1016/j.biortech.2015.06.008

Ibáñez, A. B., and Bauer, S. (2014). "Downscaled method using glass microfiber filters for the determination of klason lignin and structural carbohydrates," Biomass. Bioenerg. 68, 75-81. DOI: 10.1016/j.biombioe.2014.06.013

Kai, D., Ren, W., Tian, L., Chee, P. L., Liu, Y., Ramakrishna, S., and Loh, X. J. (2016). "Engineering poly(lactide)-lignin nanofibers with antioxidant activity for biomedical application," ACS Sustainable Chemistry \& Engineering 4(10), 5268-5276. DOI: 10.1021/acssuschemeng.6b00478

Kim, T. H., Nah, J. W., Cho, M. H., Park, T. G., and Cho, C. S. (2006). "Receptormediated gene delivery into antigen presenting cells using mannosylated chitosan/DNA nanoparticles," Journal of Nanoscience and Nanotechnology 6(9-10), 2796-2803. DOI: 10.1166/jnn.2006.434

Lam, T. B. T., Iiyama, K., and Stone, B. A. (1992). "Changes in phenolic acids from internode walls of wheat and phalaris during maturation," Phytochemistry 31(8), 2655-2658. DOI: 10.1016/0031-9422(92)83605-X

Lawoko, M., Berggren, R., Berthold, F., Henriksson, G., Gellerstedt, G. (2004). "Changes in the lignin-carbohydrate complex in softwood kraft pulp during kraft and oxygen delignification," Holzforschung 58(1), 603-610. DOI: 10.1515/ HF. 2004.114

Li, J. L., Wang, P., Yang, J., Chen, F. G., Xie, Z. J., and Xie, Y. M. (2014). "Preparation of porous biological carrier with gingko LCC and application in culture of human hepatocyte," Chemistry and Industry of Forest Products (in Chinese) 34(6), 81-87. DOI: 10.3969/j.issn.0253-2417.2014.06.013

Lin, S., and Dance, C. (1992). Methods in Lignin Chemistry, Springer Press, Berlin, GER

Ma, Z. Q., Chen, D. Y., Gu, J., Bao, B. F., and Zhang, Q. S. (2015). "Determination of pyrolysis characteristics and kinetics of palm kernel shell using TGA-FTIR and model-free integral methods," Energ. Convers. Manage. 89, 251-259. DOI: 10.1016/j.enconman.2014.09.074

Min, D. Y., Yang, C., Chiang, V., Haneekm H., and Chang, H. M. (2014). “The influence of lignin-carbohydrate complexes on the cellulase-mediated saccharification II: 
Transgenic hybrid poplars (Populus nigra L. and Populus maximowiczii A.)," Fuel 116, 56-62. DOI: 10.1016/j.fuel.2013.07.046

Muhammad, F., Guo, M., Guo, Y., Qi, W., Qu, F., Sun, F., Zhao, H., and Zhu, G. (2011). "Acid degradable $\mathrm{ZnO}$ quantum dots as a platform for targeted delivery of an anticancer drug," J. Mater. Chem. 35, 13406-13412. DOI: 10.1039/c1jm12119g

Naumann, A., Navarro-Gonzalez, M., Peddireddi, S., Kües, U., and Polle, A (2005). "Fourier transform infrared microscopy and imaging: Detection of fungi in wood," Fungal Genet. Biol. 42, 829-835. DOI: 10.1016/j.fgb.2005.06.003

Park, I. K., Yang, J., Jeong, H. J., Bom, H. S., Harada, I., Akaike, T., Kim, S. I., and Cho, C. S. (2003). "Galactosylated chitosan as a synthetic extracellular matrix for hepatocytes attachment," Biomaterials 24(13), 2331-2337. DOI: 10.1016/s01429612(03)00108-X

Sakagami, H., Kushida, T., Oizumi, T., Nakashima, H., and Makino, T. (2010). "Distribution of lignin-carbohydrate complex in plant kingdom and its functionality as alternative medicine," Pharmacol. Therapeut. 128(1), 91-105. DOI: 10.1016/j.pharmthera.2010.05.004

Shadforth, A. M., George, K. A., Kwan, A. S., Chirila, T. V., and Harkin, D. G. (2012). "The cultivation of human retinal pigment epithelial cells on Bombyx mori silk fibroin," Biomaterials 33(16), 4110-4117. DOI: 10.1016/j.biomaterials.2012.02.040

Shivakumar, M., Nagashree , K., Yallappa, S., Manjappa, S., Manjunath, K., and Dharmaprakash, M. (2017). "Biosynthesis of silver nanoparticles using prehydrolysis liquor of Eucalyptus wood and its effective antimicrobial activity," Enzyme Microb. Tech. 97, 55-62. DOI: 10.1016/j.enzmictec.2016.11.006

Singh, R. Singh, S., Trimukhe, K. D., Pandare, K. V., Bastawade, K. B., Gokhale, D. V., and Varma, A. J. (2005). "Lignin-carbohydrate complexes from sugarcane bagasse: Preparation, purification, and characterization," Carbohyd. Polym. 62(1), 57-66. DOI: 10.1016/j.carbpol.2005.07.011

Smelstorius, J. A. (1974). "Chemical composition of wood of Australian-grown Pinus radiata D. don. III. lignin-polysaccharide complexes," Holzforschung 28(3), 99-101. DOI: $10.1515 / \mathrm{hfsg} .1974 .28 .3 .99$

Takahashi, N., and Koshijima, T. (1988). "Ester linkages between lignin and glucuronoxylan in a lignin-carbohydrate complex from beech (Fagus crenata) wood," Wood. Sci. Technol. 22(3), 231-241. DOI: 10.1007/bf00386018

Vanholme, R., Demedts, B., Morreel, K., Ralph, J., and Boerjan, W. (2010). "Lignin biosynthesis and structure," Plant. Physiol. 153(3), 895- 905. DOI: 10.1104/pp.110.155119

Wu, C., Ye, Z., Le, X., Wang, P., and Xie, Y. (2016). "Preparation of porous biological carrier with aspen MWL and LCC and application in culture of human hepatocytes," Bio Chemengine (in Chinese) 50(5), 7-11. DOI: 10.3969/j.issn.16735854.2016.05.002

Xie, Y. M., Yasuda, S., Wu, H., and Liu, H. (2000). "Analysis of the structure of lignincarbohydrate complexes by the specific 13C tracer method," J. Wood Sci. 46(2), 130136. DOI: $10.1007 / \mathrm{bf00777359}$

Yaku, F., Yamada, Y., and Koshijima, T. (1976). "Lignin carbohydrate complex Pt. II. Enzymic degradation of acidic polysaccharide in Bjorkman LCC," Holzforschung 30(5), 148-156. DOI: 10.1515/hfsg.1976.30.5.148

You, T. T., Zhang, L. M., Zhou, S. K., and Xu, F. (2015). "Structural elucidation of lignin-carbohydrate complex (LCC) preparations and lignin from Arundo donax, Linn," Ind. Crop. Prod. 71, 65-74. DOI: 10.1016/j.indcrop.2015.03.070 
Zhang, H., Bai, Y., Zhou, W., and Chen, F. (2017. "Color reduction of sulfonated eucalyptus kraft lignin," Int. J. Biol. Macromol. 97, 201-208. DOI: 10.1016/j.ijbiomac.2017.01.031

Article submitted: July 26, 2017; Peer review completed: September 17, 2017; Revised version received and accepted: September 22, 2017; Published: September 26, 2017.

DOI: $10.15376 /$ biores. 12.4.8490-8504 